\title{
The association between public service motivation, work engagement and work attitudes among Chinese employees from community health service centers
}

\author{
kaipeng gan ( $\nabla$ kaipeng_gan@aliyun.com ) \\ Yunnan University of Finance and Economics \\ Yun Lin \\ Yunnan University of Finance and Economics \\ Qiu Wang \\ Yunnan University of Finance and Economics
}

\section{Research article}

Keywords: public service motivation, work engagement, job satisfaction, organizational commitment, turnover intention

Posted Date: April 5th, 2020

DOI: https://doi.org/10.21203/rs.3.rs-18820/v1

License: (c) (1) This work is licensed under a Creative Commons Attribution 4.0 International License.

Read Full License 


\section{Abstract}

Background Public service motivation (PSM) is regarded as an important psychological resource to enhance public employees' job satisfaction and organizational commitment, and lower their turnover intention. Although the relationship between PSM and individual performance has been examined extensively in previous studies, the results regarding the links between these factors still remain inconsistent. Our empirical study provides some practical implications for policy makers to improve employees' PSM through various formal or informal occupational training.

Methods We conducted a survey with 468 employees in 16 community health service centers in Yunnan province, southwest China. The associations between PSM, work engagement and work attitudes were assessed by some statistical methods including Pearson correlation, confirmatory factory analysis and structural equation modeling .

Results Employees' PSM had a direct positive effect on job satisfaction and organizational commitment respectively, but it had a direct negative effect on turnover intention. Moreover, PSM increased employees' job satisfaction and organizational commitment, and lowered employees' turnover intention through work engagement.

Conclusion The results suggest that managers in the community health service centers should assess job applicants' PSM levels in in recruitment and selection procedures and enhance employees' PSM levels through various occupational training. Further, considering the role of work engagement in shaping employees' work attitudes, policy makers should attach importance to the promoting of employees' work engagement.

\section{Background}

Since Perry and Wise [1] described PSM as "an individual's predisposition to respond to motives grounded primarily or uniquely in public institutions and organizations", research on PSM and related topics has grown significantly in several disciplines over the past two decades [2]. PSM literature argued that individuals with high levels of PSM were more likely to perform better in public organizations that allowed them to "deliver services to people with a purpose to do good for others and society" [1, 3]. Supported by many scholars, PSM theory suggested that work-related performance was enhanced greatly by individuals' PSM $[4,5]$. Many empirical studies support the premise that individuals with more prosocial tendencies or high PSM levels choose jobs in public organizations that provide the opportunities for employees to serve the public, and this choice then resulted in higher job satisfaction [6]. Kjeldsen and Andersen [7] revealed that the positive association between PSM and job satisfaction was moderated by perceived opportunity or ability to serve society and other people. Furthermore, deriving from the PersonEnvironment Fit Theory, Liu et al. [8] found a direct, positive effect of PSM on job satisfaction when both the person-organization fit and the needs-supplies fit were low among Chinese public employees. Similarly, based on a sample of civil servants employed by local governments in Korea, Kim [9] revealed 
that PSM not only was an important independent factor on job satisfaction, but it also had, through its influence on P-O fit, an indirect effect on job satisfaction. Similarly, as a psychological attachment to a particular organization $[10,11]$, organizational commitment is regarded as one of the consequences of PSM. The recent research has confirmed a positive association between PSM and organizational commitment $[12,13]$. For instance, Levitas and Vigoda-Gadot [12] suggested that PSM of public servants not only had a direct effect on their affective commitment, but it also mediated the relationship between emotional intelligence and affective commitment. Likewise, Potipiroon and Ford [14] found that PSM had a positive direct relationship with organizational commitment when high-intrinsic motivation and ethical leadership were taken into account.

In addition, recent studies also have found that PSM is linked to turnover intention of public employees. Dong et al. [5] argued that PSM not only had direct and negative effects on turnover intention, but it also mitigated the positive effects of job demands on work exhaustion and turnover intention. Indeed, individuals with high PSM levels consider their workload as a career growth opportunity or an opportunity to serve the people of community, whereas individuals with low PSM are depressed when they encounter a hindrance stressor. Even in the private sectors, individuals with a strong altruistic desire and a preference for correcting social inequity are more likely to have high job satisfaction and low intention to leave their jobs [15]. Obviously, those individuals with altruistic work values have high levels of PSM and are less likely to leave the jobs within the public sector [16].

It is widely believed that public employees are more inspired and motivated by intrinsic rewards that lead to a feeling of accomplishment rather than extrinsic rewards [1]. According to Perry and Hondeghem [3], PSM was "an individual's orientation to delivering services to people with a purpose to do good for others and society", which resulted in employees with high levels of PSM becoming engaged in more meaningful public sector jobs.

Indeed, some studies have revealed that PSM is positively related to the work engagement of public servants $[17,18]$. Citotto et al. [19] also suggested that "high levels of PSM are correlated with high levels of engagement" because jobs within the public sector were oriented towards public service, which, in turn, led public employees to work harder with higher levels of dedication, enthusiasm, and involvement. Using a large sample of Chinese public employees, Zhu et al. [20] found a strong positive association between PSM and work engagement. Similarly, the study of Cooke et al. [21] confirmed further that PSM was positively related to employees' work engagement when PSM was considered as a personal resource. On the other hand, there has been a sharp rise in academic studies that cover the antecedents and outcomes of work engagement based on the Job Demand-Resource model [22]. Scholars in public administration argue that employees with high levels of work engagement yield higher satisfaction, higher quality of service, and better service provision [23]. In theory, engaged employees have more access to job resources, personal resources, and positive emotion, all of which make them perform better in their work $[24,25]$. To this point, a majority of studies have confirmed the positive association between work engagement and job performance, such as job satisfaction [26], turnover intention [27], organizational commitment [28], and other outcome variables [29, 30]. For example, Zeynep et al. [25] suggested that 
work engagement not only had a direct effect on job performance and turnover intention, but it also mediated the relationship between affective commitment and intention to quit. Similarly, based on a sample of 220 public sector employees, Nguyen and Teo [26] found that work engagement among public sector employees was positively related to their job satisfaction. Taken together, work engagement represents a positive psychological state stemmed from work motivation, which includes altruistic motivation and PSM, has a significant relationship with work-related outcomes and job performance, such as job satisfaction, organizational commitment and low turnover intention. Thus, it can be expected that work engagement will play a key role in the link between employees' PSM and their work attitudes.

Overall, the literature on PSM has already confirmed that PSM had a direct effect on individual workrelated outcomes, such as job satisfaction, organizational commitment, and turnover intention [31, 32]. However, although previous studies have provided evidence for this view that PSM shapes employees' work attitudes and behavior significantly in the public sector [33, 34, 35], some empirical results have revealed that the effect of PSM on work-related performance is mixed [34, 36]. Perry et al. [2] suggested that for the link between PSM and individual work-related performance, it was necessary for researchers to merit careful attention to the role of intermediate variables, "including the direction of causality and the roles of intervening variables". In addition, recent studies have suggested that engaged employees are more likely to exert more effort to achieve goals and to commit to public interests with a strong sense of duty $[8,37,38]$. Adopting Perry et al.'s perspective [2], the present study devotes attention to the mediating role of work engagement. To our knowledge, it is possible that work engagement is the missing link that explains the disputed relationship between PSM and individual work-related outcomes.

\section{Methods}

\section{Participants and sample}

To collect data, we obtained access to the human resource office of Kunming Health Bureau in Yunnan province, China. We randomly selected 500 employees to participate the survey from 16 Community Health Service Centers in Kunming city. Each participant was asked to complete the questionnaire anonymously. Eventually, we obtained 468 completed surveys with an overall response rate of $93.6 \%$ after deleting 32 cases with missing data.

Of the 468 employees, 238 (50.9\%) were male and 230 (49.1\%) were female (Table 1$)$. A majority of the participants were married (58.1\%), had one or more children (63.7\%), had a non-management role $(61.1 \%)$, and worked $8-12$ hours per week (69.6\%). In terms of age, $34(7.3 \%)$ were $18-25$ years old, 179(38.2\%) were $26-30$ years old, $182(38.9 \%)$ were $31-40$ years old, $10(2.1 \%)$ were $41-50$ years old, and $63(13.5 \%)$ were over 50 years old. As for educational attainment, $27.4 \%$ held masters or doctoral degrees, $59.2 \%$ held bachelor degrees, $8.3 \%$ held a diploma, and $5.1 \%$ were high school graduates or did not graduated high school. In terms of work tenure, 166 (35.5\%) had worked for 5 years or less, $123(26.3 \%)$ had worked for $6-10$ years, 42 (9.0\%) had worked for $11-15$ years, $29(6.2 \%)$ had worked for $16-20$ years, and $108(23.1 \%)$ had worked for more than 21 years. 
Table 1

Descriptive statistics of participants in the present study.

\begin{tabular}{|c|c|c|c|c|c|c|c|}
\hline Variables & Categories & $\mathbf{N}$ & $\%$ & Variables & Categories & $\mathbf{N}$ & $\%$ \\
\hline \multirow[t]{2}{*}{ Gender } & Male & 238 & $50.9 \%$ & \multirow[t]{2}{*}{ Child } & With children & 298 & $63.7 \%$ \\
\hline & Female & 230 & $49.1 \%$ & & $\begin{array}{l}\text { without } \\
\text { children }\end{array}$ & 170 & $36.3 \%$ \\
\hline \multirow[t]{5}{*}{ Age } & $18-25$ & 34 & $7.3 \%$ & \multirow[t]{5}{*}{ Work tenure } & 5 years or less & 166 & $35.5 \%$ \\
\hline & $26-30$ & 179 & $38.2 \%$ & & $6-10$ years & 123 & $26.3 \%$ \\
\hline & $31-40$ & 182 & $38.9 \%$ & & $11-15$ years & 42 & $9.0 \%$ \\
\hline & $41-50$ & 10 & $2.1 \%$ & & $16-20$ years & 29 & $6.2 \%$ \\
\hline & 51 or older & 63 & $13.5 \%$ & & $\begin{array}{l}21 \text { years or } \\
\text { more }\end{array}$ & 108 & $23.1 \%$ \\
\hline \multirow{3}{*}{$\begin{array}{l}\text { Marital } \\
\text { status }\end{array}$} & Single & 185 & $39.5 \%$ & \multirow{3}{*}{$\begin{array}{l}\text { Working } \\
\text { hours }\end{array}$} & 8 hours or less & 131 & $28.0 \%$ \\
\hline & Married & 272 & $58.1 \%$ & & $8-12$ hours & 326 & $69.6 \%$ \\
\hline & $\begin{array}{l}\text { Divorced/ } \\
\text { Widowed }\end{array}$ & 11 & $2.4 \%$ & & $\begin{array}{l}12 \text { hours or } \\
\text { more }\end{array}$ & 11 & $2.4 \%$ \\
\hline \multirow[t]{4}{*}{ Education } & $\begin{array}{l}\text { High school or } \\
\text { below }\end{array}$ & 24 & $5.1 \%$ & \multirow[t]{4}{*}{$\begin{array}{l}\text { Managerial } \\
\text { level }\end{array}$} & $\begin{array}{l}\text { Non- } \\
\text { management }\end{array}$ & 286 & $61.1 \%$ \\
\hline & Diploma & 39 & $8.3 \%$ & & Lower & 128 & $27.4 \%$ \\
\hline & Bachelor & 277 & $59.2 \%$ & & Middle & 47 & $10.0 \%$ \\
\hline & Masters/Doctoral & 128 & $27.4 \%$ & & Upper & 7 & $1.5 \%$ \\
\hline
\end{tabular}

\section{Measures}

\section{Public service motivation}

Public service motivation was measured using a shortened version of the PSM scale which adopted five items from Perry's original scale [39]. The 5-item measure was widely verified and used [40, 41], and included commitment to public interest, self-sacrifice, compassion and social justice. A sample item was "Meaningful public service is very important to me." All items were rated on a 5-point Likert-type scale with anchors that ranged from 1 (strongly disagree) to 5 (strongly agree). Cronbach's alpha of these five items was 0.835 .

\section{Job satisfaction}

Job satisfaction was assessed using a 4-item scale developed by Boateng and Hsieh [42]. Sample items included "overall, I am satisfied with my current job" and "I have plans to look for a better job elsewhere". 
All items were measured using a 5-point Likert-type scale with anchors that ranged from 1 (strongly disagree) to 5 (strongly agree). Cronbach's alpha of this scale was 0.839 .

\section{Organizational commitment}

Organizational commitment was measured with four items from the original scale of Meyer et al. [43]. Sample items included "I feel a strong sense of belonging to my organization", "my organization has a great deal of personal meaning for me", "I feel emotionally attached to my organization" and "I feel like part of the family in my organization." Participants answered items on a 5-point Likert-type scale that ranged from 1 (strongly disagree) to 5 (strongly agree). Cronbach's alpha of this scale was 0.884 .

\section{Turnover intention}

Turnover intention was measured using a 4-item scale developed by Kim et al. [44]. Sample items included "I intend to leave my organization" and "I intend to stay in my present organization as long as possible". Participants answered items on a 5-point Likert-type scale ranging from 1 (strongly disagree) to 5 (strongly agree). Cronbach's alpha was 0.858 .

\section{Work engagement}

Work engagement was measured using a three items adopted from the Utrecht Work Engagement Scale developed by Schaufeli and Bakker [45]. Sample items included "At my work, I feel bursting with energy" (vigor), "I am immersed in my work" (absorption), and "I am enthusiastic about my job" (dedication). Participants answered items on a 5-point Likert-type scale that ranged from 1 (strongly disagree) to 5 (strongly agree). Cronbach's alpha was 0.743 .

\section{Analytical strategy}

In the present study, the descriptive analysis, correlation analysis, confirmatory factory analysis (CFA) and structural equation modeling (SEM) were analyzed using SPSS 22.0 and AMOS 24.0. First, we used confirmatory factory analysis (CFA) to test convergent, discriminant validity and model fit of all the scales in the present study. Three fit indices were used to assess the model fit: Tucker-Lewis index (TLI), comparative fit index $(\mathrm{CFI})$, and root mean square error of approximation (RMSEA). Compared with other alternative models, the hypothesized five-factor model had a better fit $\left(X^{2}(160)=411.802, p<0.001 ; \chi\right.$ $2 / \mathrm{df}=2.574, \mathrm{CFI}=0.947, \mathrm{TLI}=0.937, \mathrm{RMSEA}=0.058)$, which provided evidence for discriminant validity of the five-factor model.

Second, structural equation modeling (SEM) was applied to investigate the multiple relationships between the dependent and independent variables. We tested whether PSM had direct effects on employees' attitudes and work engagement. Then, we also tested whether the relationship between PSM and work-related attitudes was mediated by work engagement. In addition, the biased-corrected bootstrapping method of mediation test was used to analyze the indirect effects and mediated effect [46]. 


\section{Results}

\section{Descriptive statistics and Correlations}

The means, standard deviations, and correlations among study variables were presented in Table 2. PSM was positively correlated with job satisfaction $(r=0.485, p<0.01)$ and organizational commitment $(r=$ $0.455, p<0.01)$, but negatively related to turnover intention $(r=-0.420, p<0.01)$. Moreover, work engagement was positively related to job satisfaction $(r=0.688, p<0.01)$ and organizational commitment $(r=0.545, p<0.01)$. Consistent with previous research [25], work engagement was negatively related to turnover intention $(r=-0.537, p<0.01)$.

Table 2

Means, standard deviations and correlations among variables in the present study.

\begin{tabular}{|c|c|c|c|c|c|c|c|}
\hline & Mean & SD & 1 & 2 & 3 & 4 & 5 \\
\hline 1. Public service motivation & 3.753 & 0.6156 & 1 & & & & \\
\hline 2. Work engagement & 3.873 & 0.5756 & $0.457 * \star$ & 1 & & & \\
\hline 3. Job satisfaction & 3.627 & 0.6203 & $0.485^{\star \star}$ & $0.688 * *$ & 1 & & \\
\hline 4. Organizational commitment & 3.762 & 0.6437 & $0.455^{\star \star}$ & $0.545^{\star \star}$ & $0.671^{\star *}$ & 1 & \\
\hline 5. Turnover intention & 2.306 & 0.6535 & $-0.420 * \star$ & $-0.537 * \star$ & $-0.609 * \star$ & $-0.662^{\star \star}$ & 1 \\
\hline
\end{tabular}

\section{Path analysis}

Regarding the structural model, we first tested a default model without mediating variables. The results indicated that the default model yielded an acceptable fit to the data $\left(\chi^{2}(109)=267.416, p<0.001 ; \chi\right.$ $2 / \mathrm{df}=2.453, \mathrm{CFI}=0.960, \mathrm{TLI}=0.950, \mathrm{RMSEA}=0.056)$. In the regression equation without the mediator, the standardized coefficients revealed that PSM had a positive effect on job satisfaction $(\beta=0.85, p<$ 0.001 ), organizational commitment $(\beta=0.93, p<0.001)$, and a negative effect on turnover intention ( $\beta=$ $-0.82, \mathrm{p}<0.001)$.

Subsequently, we tested the hypothesized model that included a mediator (i.e., work engagement). When the mediator was added to the regression equation (Fig. 1), the hypothesized model demonstrated an adequate fit $\left(\chi^{2}(164)=460.672, p<0.001 ; \chi^{2} / d f=2.809, \mathrm{CFI}=0.938, \mathrm{TLI}=0.928\right.$, RMSEA $\left.=0.062\right)$. In the hypothesized model, significant paths were found from PSM to work engagement $(\beta=0.481, p<0.001)$, and from work engagement to job satisfaction $(\beta=0.786, p<0.001)$, organizational commitment $(\beta=$ $0.803, p<0.001)$, and turnover intention $(\beta=-0.779, p<0.01)$.

Finally, to assess whether work engagement mediate the relationship between PSM and work attitudes, the bootstrapping method with 1,000 samples was used to test the significance of the indirect effects. 
These bootstrapping results indicated that the indirect effects of PSM on participants' job satisfaction (standardized estimate $=0.378, \mathrm{p}<0.001, \mathrm{Cl}[0.295,0.461]$ ), organizational commitment (standardized estimate $=0.386, \mathrm{p}<0.001, \mathrm{Cl}[0.281,0.506]$ ), and turnover intention (standardized estimate $=-0.374, \mathrm{p}<$ $0.001, \mathrm{Cl}[-0.500,-0.273])$ through work engagement were all significant, because the $95 \%$ Confidence Interval did not include zero [46].

Table 4

Direct and indirect effects and bootstrap analysis of $95 \%$ confidence intervals $(\mathrm{Cl})$.

\begin{tabular}{|c|c|c|c|c|}
\hline \multirow[t]{2}{*}{ Relationship } & \multirow[t]{2}{*}{ Standardized Coefficient } & \multirow[t]{2}{*}{ SE } & \multicolumn{2}{|c|}{ Bootstrapping (95\%) C } \\
\hline & & & Lower & Upper \\
\hline \multicolumn{5}{|l|}{ Direct Effect } \\
\hline $\mathrm{PSM} \rightarrow \mathrm{WE}$ & $0.481^{\star \star \star}$ & 0.060 & 0.362 & 0.593 \\
\hline PSM $\rightarrow$ JS & $0.242^{\star \star}$ & 0.042 & 0.158 & 0.321 \\
\hline $\mathrm{PSM} \rightarrow \mathrm{OC}$ & $0.137^{*}$ & 0.056 & 0.026 & 0.246 \\
\hline $\mathrm{PSM} \rightarrow \mathrm{TI}$ & -0.082 & 0.060 & -0.196 & 0.039 \\
\hline WE $\rightarrow$ JS & $0.786^{\star \star \star}$ & 0.047 & 0.688 & 0.869 \\
\hline WE $\rightarrow$ OC & $0.803^{\star \star \star}$ & 0.042 & 0.717 & 0.882 \\
\hline $\mathrm{WE} \rightarrow \mathrm{TI}$ & $-0.779 * \star$ & 0.050 & -0.876 & -0.677 \\
\hline \multicolumn{5}{|l|}{ Indirect Effect } \\
\hline $\mathrm{PSM} \rightarrow \mathrm{WE} \rightarrow \mathrm{JS}$ & $0.378 * \star \star$ & 0.042 & 0.295 & 0.461 \\
\hline $\mathrm{PSM} \rightarrow \mathrm{WE} \rightarrow \mathrm{OC}$ & $0.386^{\star \star \star}$ & 0.058 & 0.281 & 0.506 \\
\hline $\mathrm{PSM} \rightarrow \mathrm{WE} \rightarrow \mathrm{TI}$ & $-0.374^{\star \star \star}$ & 0.057 & -0.500 & -0.273 \\
\hline \multicolumn{5}{|l|}{ Total Effect } \\
\hline PSM $\rightarrow$ JS & $0.620 * \star \star$ & 0.047 & 0.521 & 0.707 \\
\hline $\mathrm{PSM} \rightarrow \mathrm{OC}$ & $0.523^{\star \star \star}$ & 0.051 & 0.420 & 0.617 \\
\hline $\mathrm{PSM} \rightarrow \mathrm{TI}$ & $-0.456 * \star \star$ & 0.054 & -0.559 & -0.344 \\
\hline
\end{tabular}

\section{Discussions}

Recently, much of the research has focused on the link between PSM and individual outcomes, such as organizational commitment, job satisfaction, or turnover intention, but the results from these recent works 
are mixed. For example, some P-O fit research argues that the direct effect of PSM on work attitudes is not significant, but is fully mediated by the extent to which the person-environment was fit $[47,48]$. Furthermore, some findings also show that the relationship between PSM and work attitudes is dependent on some organizational characteristics, such as ethical leadership, performance goal, or red tape $[14,49]$. Contrary to these findings, however, some results in recent years have revealed that PSM has a direct effect on the employees' work attitudes $[15,9,50]$. In this study, we examined the role of work engagement in the relationship between PSM and work attitudes among Chinese employees in the community health service centers. First, consistent with previous findings [8], our results also confirmed the direct effect of PSM on work attitudes. The more employees are committed to the public interest, the greater levels of job satisfaction and organizational commitment they have. Moreover, employees with a high level of PSM are more likely to stay in the public sector because the employees' PSM is negatively related to their turnover intention [5]. However, when work engagement was taken into account, PSM had positive direct effects on both job satisfaction and organizational commitment, but it had no direct effect on employees' turnover intention.

Second, our findings revealed that work engagement was associated with work attitudes. This finding is important for understanding how employees' work engagement improves their levels of job satisfaction and commitment to their organization, and it plays an important role in reducing their intention to leave a job. In agreement with previous findings [8,5], our study showed that employees with high levels of work engagement were more likely to feel satisfied with their jobs, formed greater commitment to public organizations, and it diminished their desire to change jobs.

Finally, our study confirmed that the relationship between PSM and work attitudes was mediated by work engagement. Our results indicated that PSM was related to employees' work engagement, which in turn, increased the levels of job satisfaction and organizational commitment, and decreased the intention to leave a job within the community health service centers. This result suggests that when employees' PSM is high, their work engagement may increase, which will, in turn, enhance employees' job satisfaction and organizational commitment, and decrease employees' turnover intention. As previous research suggests, when employees with high levels of PSM fully involve themselves in jobs, they have greater levels of job satisfaction and organizational commitment, and they also prefer to stay in public sector [8].

\section{Theoretical and practical implications}

Our findings suggested that PSM not only had a direct relationship with work attitudes when mediating variables did not consider, but it also had an indirect effect on work attitudes through its influence on work engagement. Thus, our results indicated that both PSM and work engagement accounted for work attitudes collectively, which led to the following theoretical implications. First of all, it confirmed that PSM had indirect effects on work attitudes through work engagement, which contributed to the claims of PSM theory [1]. The results suggested that something like PSM played an important role in serving the public because employees with high PSM levels achieved self-worth from their work in the public organization. In other words, PSM acts as a psychological coping mechanism that allows individuals to fulfill their 
altruistic needs, to serve the public, and to maintain their status as excellent employees in the public organization [5].

Secondly, our findings also showed that work engagement had a significant effect on work attitudes. This result is significant because previous studies have revealed that work engagement is significantly related to individual outcomes, such as high job satisfaction, absenteeism, and turnover [51, 52]. Accordingly, this result suggested that researchers should rethink the significant direct effect of work engagement on work attitudes and the role of work engagement in the link between PSM and individual work attitudes. Overall, given that employees' work attitudes were significantly correlated with work engagement, our findings indicated that scholars should attach importance to the role that work engagement plays in increasing employees' job satisfaction and organizational commitment, and in reducing their intention to quit their job within the public organization.

Our results also provided some practical implications for managers in the community health service centers. Given that PSM is a key component of shaping employees' work perception and behaviors, public organizations should investigate job seekers' altruistic motivation in recruitment and selection procedures, and they should assess whether the job seekers' personal values are consistent with public organizations [3]. In addition, our findings indicated that public organizations should promote employee's favorable work engagement and work attitudes, and build public service culture through formal and informal training $[5,37]$.

\section{Limitations}

Of course, our study has some limitations. First, our study used a shortened version of Perry's PSM scale, which may have affected our results. Although the shortened version of the PSM scale with five items was widely used in the different institutional contexts in previous research [41], we should develop a PSM scale based on the Chinese historical and institutional contexts in future research. Second, our study relied on cross-sectional self-reported data and, therefore, it did not offer a clear causal relationship [37]. It would be worthwhile for researchers to use a panel or longitudinal data to avoid the potential for common method biases. Third, our study concentrated on the psychological levels of employees in exploring work attitudes, but some important external key variables (cultural background, race, and particular institutional characteristics for example) might affect employees' work-related behavior. In a traditional Chinese society, Confucian culture has far-reaching influence on an individual's attitudes and behavior. Therefore, future studies should consider this influential factor at individual, organizational, and national levels, which will affect the associations between PSM and work attitudes and behaviors.

\section{Conclusion}

Despite the above-mentioned limitations, our study aimed to explore the mediating effects of work engagement in the relationship between PSM and work attitudes of employees from community health service centers. Our findings revealed that PSM not only had a direct effect on employee's work attitudes but it also had, through work engagement, an indirect effect on employee's work attitudes. More 
importantly, our study contributes to the PSM theory and literature by examining the critical role of PSM and work engagement in shaping employees' work-related perception and behavior in a Chinese context. We hope that our research encourages more studies to explore the potentially complicated associations between PSM and work-related attitudes and behaviors in the public organizations.

\section{Declarations}

\section{Abbreviations}

PSM: public service motivation; WE: work engagement; JS: job satisfaction; OC: organizational commitment; TI: turnover intention; CFI: Comparative fit index; TLI: Tucker-Lewis index; RMSEA: Root mean square error of approximation; DF: Degrees of freedom; ${ }^{2} / D F$ : Likelihood ratio; SD: Standard deviation; SEM: Structural equation model.

\section{Ethics approval and consent to participate}

This study was approved by Ethical Committee of Yunnan University of Finance and Economics. All participants consented to participate in this study on a voluntary and anonymous basis. Therefore, completing the questionnaire was supposed 'informed consent' for participation in the survery.

\section{Consent for publication}

Not applicable

\section{Availability of data and materials}

The datasets used in the current study are available from the corresponding author on reasonable request.

\section{Competing interests}

The authors declare that they have no competing interests.

\section{Funding}

No funding was obtained for this study. 


\section{Author Contributions:}

1. W. contributed to data analysis. Y. L. provided thorough review and K. G. wrote the draft and edited the paper. All authors have read and approved the final manuscript.

\section{Acknowledgements}

The authors thank the 468 employees who actively participated in this survey and the leaders from 16 Community Health Service Centers in Kunming city. We would also like to thank all the students who were involved in the data collection.

\section{Author details}

School of Finance and Public Administration, Yunnan University of Finance and Economics, No. 237, Longquan road, Kunming 650221, China

\section{References}

1.

Perry JL, Wise LR. The motivational bases of public service. Public Adm Rev. 1990;50:367-73.

2.

Perry JL, Hondeghem A, Wise LR. Revisiting the motivational bases of public service: Twenty years of research and an agenda for the Future. Public Adm Rev. 2010;70:681-90.

3.

Perry JL, Hondeghem A. Building theory and empirical evidence about public service motivation. Int Public Manag J. 2008;11:3-12.

4.

Kim SW, Vandenabeele W, Wright BE, Andersen LB, Cerase FP, Christensen RK, Desmarais C, et al. Investigating the structure and meaning of public service motivation across populations: developing an international instrument and addressing issues of measurement invariance. J Publ Adm Res Theory. 2013;23:79-102.

5 .

Shim DC, Park HH, Eom TH. Street-level bureaucrats' turnover intention: Does public service motivation matter? Int Rev Adm Sci. 2017;83:563-82.

6.

Vandenabeele W. Government calling: Public service motivation as an element in selecting government as an employer of choice. Public Adm. 2008;86:1089-105. 
7.

Andersen LB, Kjeldsen AM. Public service motivation, user orientation and job satisfaction: A question of employment sector? Int Public Manag J. 2013;12:252-74.

8.

Liu BC, Tang TLP, Yang KF. When does public service motivation fuel the job satisfaction fire? The joint moderation of person-organization fit and needs-supplies fit. Public Manag Rev. 2015;17:876-900.

9.

Kim S. Does person-organization fit matter in the public-sector? Testing the mediating effect of personorganization fit in the relationship between public service motivation and work attitudes. Public Adm Rev. $2012 ; 72(6): 830-40$.

10.

O'Reilly C, Chatman J. Organizational commitment and psychological attachment: The effect of compliance, identification, and internalization on prosocial behavior. J Appl Psychol. 1986;71:492-9. 11.

Allen NJ, Meyer JP. Organizational commitment: Evidence of career stage effects? J Bus Res. 1993;26:49-61.

12.

Levitats Z, Vigoda-Gadot E. Yours emotionally: How emotional intelligence infuses public service motivation and affects the job outcomes of public personnel. Public Adm. 2017;95:759-75.

13.

Caillier JG. Does public service motivation mediate the relationship between goal clarity and both organizational commitment and extra-role behaviors? Public Manag Rev. 2016;18:300-18.

14.

Potipiroon W, Ford MT. Does public service motivation always lead to organizational commitment? Examining the moderating roles of intrinsic motivation and ethical leadership. Public Personnel Manage. 2017;46:211-38.

15.

Choi YJ, Chun IH. Effects of public service motivation on turnover and job satisfaction in the US teacher labor market. Int J Publ Admin. 2018;41:172-80.

16.

$\mathrm{Xu} \mathrm{H}$. Research on the influence of career value orientation of young civil servants on turnover intention: An empirical analysis based on different length of service groups (in Chinese). Chin Public Adm. 2017;379:34-8.

17.

Bakker AB. A job demands-resources approach to public service motivation. Public Adm Rev. 2015;75:723-32.

18.

Jin $\mathrm{MH}$, Mcdonald B. Understanding employee engagement in the public sector: The role of immediate supervisor, perceived organizational support, and learning opportunities. Amer Rev Public Adm. 2017:47:881-97. 
19.

Simone SD, Citotto G, Pinna R, Giustiniano L. Engaging public servants: Public service motivation, work engagement and work-related stress. Manag Decis. 2016;54:1569-94.

20.

Zhu GN, Li M, Yan, M. A Research on the effects of government employees' public service motivation on job involvement (in Chinese). Chin Public Adm Rev. 2012;1:122-44.

21.

Cooke DK, Brant KK, Woods JM. The role of public service motivation in employee work engagement: A test of the job demands-resource model. Int J Publ Admin. 2018;73:1-11.

22.

Baker AB, Demerouti E. Job demands-resource theory: taking stock and looking forward. J Occup Health Psychol. 2016;22(3):273-85.

23.

Vigoda-Gadot E, Eldor L, Schohat LM. Engage them to public service: Conceptualization and empirical examination of employee engagement in public Administration. Amer Rev Public Adm. 2013;43:518-38. 24.

Letiter MP, Bakker AB. “Work engagement: introduction”. In: Bakker AB, Leiter MP, editors. Work Engagement: A Handbook of Essential Theory and Research. New York: Psychology Press; 2010. pp. 1-9. 25.

Yalabik ZY, Popaitoon P, Chowne JA, Rayton BA. Work engagement as a mediator between employee attitudes and outcomes. Int J Hum Resour Manag. 2013;24:2799-823.

26.

Nguyen DTN, Teo STT, Pick D, Jemail M. Cynicism about change, work engagement, and job satisfaction of public sector nurses. Aust J Public Adm. 2017;77(2):172-86.

27.

Brad S, ThomasG R, TonetteS R. Employee engagement: An examination of antecedent and outcome variables. Hum Resour Dev J. 2011;14:427-45.

28.

Albdour AA, Altarawneh II. Employee engagement and organizational commitment: Evidence from Jordan. Int J Bus. 2014;19:192-212.

29.

Gorgievski MJ, Bakker AB, Schaufeli WB. Work engagement and workaholism: Comparing the selfemployed and salaried employees. J Posit Psychol. 2010;5:83-96.

30.

Liat E. Looking on the bright side: The positive role of organizational politics in the relationship between employee engagement and performance at work. Appl Psychol Int Rev. 2017;66:233-59.

31.

Kim S. Testing a revised measure of public service motivation: reflective versus formative specification. J Publ Adm Res Theory. 2011;21:521-46.

32. 
Park SM, Rainey HG. Leadership and public service motivation in US federal agencies. Int Public Manag J. 2008;11:109-42.

33.

Moynihan DP, Pandey SK. The role of organizations in fostering public service motivation. Public Adm Rev. 2007;67:40-53.

34.

Vandenabeele W. The mediating effect of job satisfaction and organizational commitment on selfreported performance: more robust evidence of the PSM-performance relationship. Int Rev Adm Sci. 2009;75:11-34.

35.

Potipiroon W, Ford MT. Does public service motivation always lead to organizational commitment? Examining the moderating roles of intrinsic motivation and ethical leadership. Public Personnel Manage. 2017;46:211-38.

36.

Gould-Williams JS, Mostafa AMS, Bottomley P. Public service motivation and employee outcomes in the Egyptian public sector: Testing the Mediating Effect of Person-Organization Fit. J Publ Adm Res Theory. 2015;25:597-622.

37.

Wright BE, Adam MG. Unanswered questions about public service motivation: Designing research to address key issues of emergence and effects. Public Adm Rev. 2010;70:691-700. 38 .

Kim T, Henderson AC, Eom TH. At the front line: Examining the effects of perceived job significance, employee commitment, and job involvement on public service motivation. Int Rev Adm Sci. 2015;8:71333.

39.

Perry JL. Measuring public service motivation: An assessment of construct reliability and validity. J Publ Adm Res Theory. 1996;6:5-22.

40.

Christensen RK, Wright BE. The effects of public service motivation on job choice decisions:

Disentangling the contributions of person-organization fit and person-job fit. J Publ Adm Res Theory. 2011;21(4):723-43.

41.

Qi FH, Wang WJ. Employee involvement, public service motivation, and perceived organizational performance: testing a new model. Int Rev Adm Sci. 2018;84:746-64.

42.

Boateng FD, Hsieh ML. Explaining job satisfaction and commitment among prison officers: The role of organizational justice. Prison J. 2019;99:172-93.

43.

Meyer JP, Allen NJ, Smith CA. Commitment to organization and occupations: Extension and test of a three-component conceptualization. J Appl Psychol. 1993;78:538-51. 
44.

Kim SW, Price JL, Mueller CW, Watson TW. The determinants of career intent among physicians at a US Air Force hospital. Hum Relat. 1996;49:947-75.

45.

Schaufeli WB, Bakker AB. Job demands, job resources, and their relationship with burnout and engagement: A mulit-sample study. J Organ Behav. 2004;25:293-315.

46.

Preacher KJ, Hayes AF. Asymptotic and resampling strategies for assessing and comparing indirect effects in multiple mediator models. Behav Res Methods. 2008;40:879-91.

47.

Bright L. Does public service motivation really make a difference on the job satisfaction and turnover intentions of public employees? Amer Rev Public Adm. 2008;38:149-146.

48.

Steijn B. Person-environment fit and public service motivation. Int Public Manag J. 2008;11:13-27. 49.

Kjeldsen AM, Hansen JR. Sector differences in the public service motivation-job satisfaction relationship: Exploring the role of organizational characteristics. Rev Public Pers Adm. 2018;38:24-48. 50.

Taylor J. Public service motivation, relational job design, and job satisfaction in local government. Public Adm. 2014;92:902-18.

51.

Agarwal UA, Datta S, Blake-Beard S, Bhargava S, Linking. LMX, innovative work behavior and turnover intentions: The mediating role of work engagement. Career Dev Int. 2012;17:208-30.

52.

Timms C, Brough P, O’Driscoll M, Kalliath T, Siu OL, Sit C, Lo D. Flexible work arrangements, work engagement, turnover intentions and psychological health. Asia Pac J Hum Resour. 2015;53:83-103.

\section{Figures}




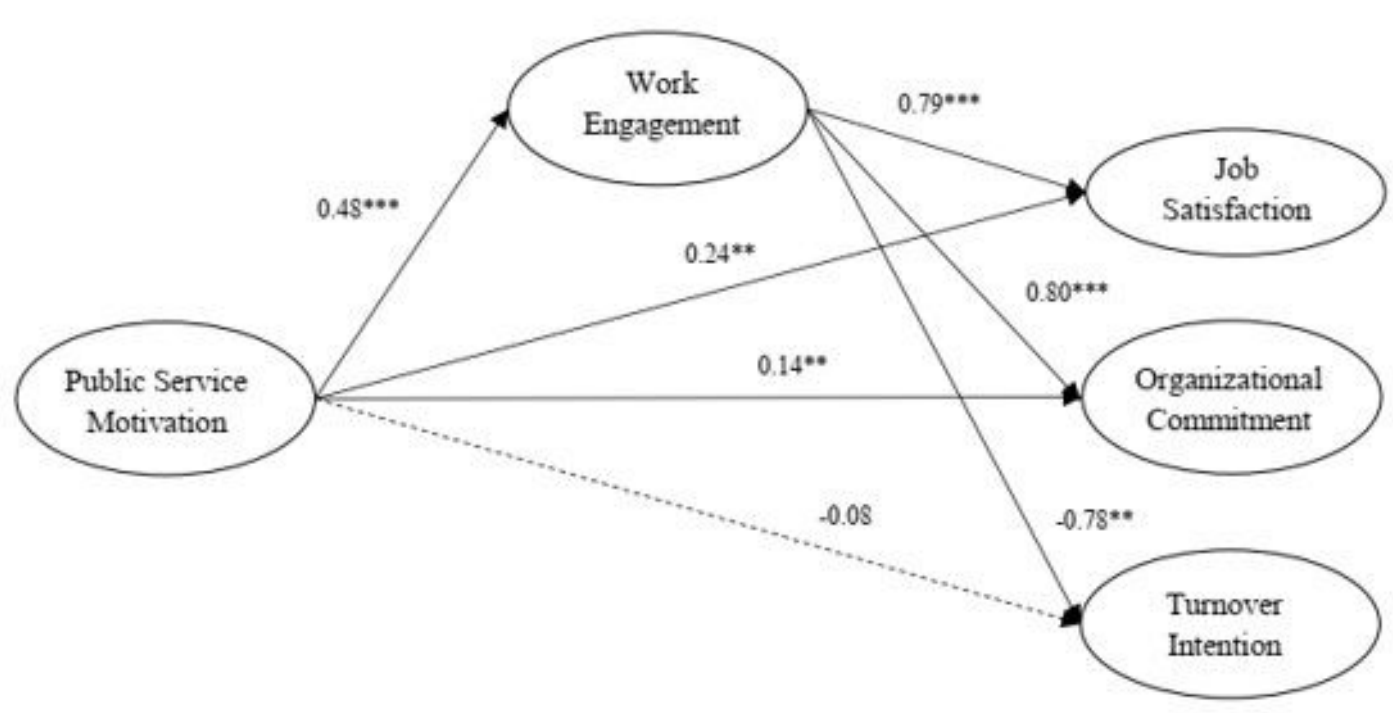

Figure 1. The mediating role of work engagement between PSM and work attitudes. Note: ${ }^{*} p<0.05, * * p<0.01, * * * p<0.001$. chi square $=460.672 ;$ degrees of freedom $=164, p<0.001 ;$ CFI $=0.938 ;$ TLI $=0.928 ;$ RMSEA $=0.062$.

\section{Figure 1}

The mediating role of work engagement between PSM and work attitudes. Note: ${ }^{*} p<0.05, * \star p<0.01$, $* \star \star$ $\mathrm{p}<0.001$. chi square $=460.672$; degrees of freedom $=164, \mathrm{p}<0.001 ; \mathrm{CFI}=0.938 ; \mathrm{TLI}=0.928 ; \mathrm{RMSEA}=$ 0.062 .

\section{Supplementary Files}

This is a list of supplementary files associated with this preprint. Click to download.

- data.xlsx 